1960) and a central effect (Gillespie et al., 1962) may play some part. Agar et al. (1958) discussed the underlying theories of pre-eclamptic hypertension production in view of mecamylamine and the ganglion-blocking hypotensive agents being ineffectual in controlling this condition. Recently, Senior et al. (1963) have suggested that 5-hydroxytryptamine (serotonin) may have some role in the production of toxaemia of pregnancy and that antagonists of this substance may be of value in treatment. It is of interest that methyldopa interferes with the formation of serotonin in the body (Oates et al., 1960).

\section{Summary}

Methyldopa and the chlorothiazide diuretics have been used in 15 patients with severe pre-eclamptic toxaemia. All but one showed a marked and satisfactory fall in blood-pressure, a diminution in proteinuria, and improvement in well-being.

The foetus died early in treatment in three patients. All three had severe toxaemia occurring early in the third trimester and showed blood ureas above normal-one of them had the unsuccessful blood-pressure response. The other patients were able to continue with the pregnancies and all were delivered of healthy normal babies except one baby who died of an obstetric cause.

The dose of methyldopa was relatively small and the only complication was a drug rash, but other drugs were being given at the same time. However, the number of patients was small and other side-effects may occur. No deterioration has been noted in following the condition of these patients.

We should like to thank Mr. Alan Brews for permission to publish his cases.

\section{REFERENCES}

Agar, H., Barrett, C. T. H., and Exley, K. A. (1958). 7. Obstet. Gynaec. Brit. Cwlth, 65, 378.

Assali, N. S., Judd, L., Mondz, N., and Dasgupta, K. (1958). F. Lab. clin. Med., 52, 423.

Bayliss, R. I. S., and Harvey-Smith, E. A. (1962). Lancet, 1, 763.

Dollery, C. T., and Harington, M. (1962). Ibid., 1, 759.

Gillespie, L., Oates, J. A., Crout, J. R., and Sjoerdsma, A. (1962). Circulation, 25, 281

Hamilton, M., and Kopelman, H. (1963). Brit. med. F., 1, 151.

Landesman, R., Ollstein, R. N., and Quinton, K. J. (1959). N.Y. St. F. Med., 59, 66.

McClure Browne, J. C. (1963). In Modern Trends in Obstetrics, edited by R. J. Kellar, p. 1. Butterworth, London.

Oates, J. A., Gillespie, L., Undenfriend, S., and Sjoerdsma, A. (1960). Science, 131, 1890 .

Riedel, J. A. (1963a). F. Obstet. Gynaec. Brit. Cwlth, 70, 456.

- (1963b). Ibid., 70, 145.

Senior, J. B., Fahim, I., Sullivan, F. M., Robson, J. M. (1963). Lancet, 2, 553 .

Tennent, R. A., and Leslie, D. W. (1960). Scot. med. 7., 5, 113.

Townsend, S. L. (1963). In Modern Trends in Obstetrics, edited by R. J. Kellar, p. 15. Butterworth, London.

West, G. B. (1962). F. Pharm. Pharmacol., 14, 828.

\title{
Controlled Trial of Chlorothiazide in Treatment of Early Pre-eclampsia
}

\author{
D. N. MENZIES,* M.B., CH.B., F.R.C.S.ED., M.R.C.o.G.
}

Brit. med. F., 1964, 1, 739-742

Pre-eclampsia remains a common complication of pregnancy in this country. Although the foetal wastage appears to be slightly less now than ten years ago, the figures from the National Birthday Trust Perinatal Mortality Survey show that in pregnancies resulting in stillbirth or neonatal death there is still a raised incidence of pre-eclampsia (D. G. Bonham, personal communication, 1963). It is also one of the three most common features of the history where the mother has died ; $18 \%$ of maternal deaths are associated with pre-eclampsia (Ministry of Health, 1963).

In spite of the importance of the condition the cause remains obscure, and treatment, although relatively successful, is still largely empirical. Hypotensive drugs may have value if given early in pregnancy, but this treatment is possible only for those women who show early hypertension. In cases of non-toxaemic hypertension reserpine seems to have a place but does not reduce foetal loss (Landesman and Ollstein, 1958). In true preeclampsia hypotensive drugs can only be given late and the results are disappointing. A large number of clinicians still rely on prescribing a sedative and advising bed rest, and of these two methods rest in bed is the least empirical. It is known that the myometrial blood-flow is decreased in preeclampsia (Morris et al., 1955 ; Dixon et al., 1963), but with rest this is greatly improved (Morris et al., 1956). Rest also results in an increased urinary volume and sodium excretion (Thomas, 1957, 1959). Unfortunately, such a line of treatment * First Assistant, Obstetric Unit, University College Hospital Medical
School, London. necessitates the early admission of large numbers of women to hospital. In most units such a policy leads to overcrowding in the antenatal wards. From the patient's point of view the prolonged separation from husband and family is an intolerable strain. Many of these women prefer to decline admission and accept the risk of remaining an out-patient.

At University College Hospital, London, the demand for antenatal beds is never satisfied. In 19501,270 patients were delivered and the foetal mortality associated with pre-eclampsia (excluding essential hypertension) was $4.5 \%$. This figure was achieved by admitting, for periods ranging as high as 38 days, 48 of 66 mothers suffering from the complication. Furthermore, of the 57 surgical inductions in that year, 37 were for hypertension in pregnancy (Musgrove, 1950). Greater attention is now paid to minor signs of pre-eclampsia ; this has resulted in a greater number of diagnoses over latter years. In spite of these new diagnostic criteria there has been little improvement in the perinatal mortality. During 1960 out of a total of 1,358 delivered patients $223(16.4 \%)$ were diagnosed as having pre-eclampsia. The perinatal mortality was $3.14 \%$. To produce this reduction of less than $1.4 \%$ all but 48 were admitted to hospital-that is, 175 women spent up to a maximum of 90 days in hospital (Woolf, 1960). Eighty-four were in hospital for up to a week before delivery, and 35 for more than a week but not more than two weeks. Prolonged treatment was required by 56,38 of them remaining in the ward until the third week and 18 requiring more than a month in hospital. Of all these women 114 were treated by induction. This in all amounts to a hospital-bed occupancy of 2,480 days per year or a ward 
of seven beds allocated solely to the treatment of pre-eclampsia. As only $175(44 \%)$ women out of a total of 396 antenatal admissions suffered from pre-eclampsia, the estimated total number of antenatal beds required should be not fewer than 16, nearly a third of the total beds in our unit. Any economy in such bed usage is likely to be welcomed by both patient and clinician.

A line of therapy which enabled the obstetrician to delay admission would therefore be of benefit, and it appeared that the thiazide group of diuretics might be well suited for this purpose.

The main properties of the drugs are that they cause a diuresis, increase sodium excretion, and antagonize noradrenaline (Wilson, 1963). There is also a hypotensive action which cannot be solely explained by relating it to increased salt excretion (Pickering et al., 1961 ; Villarreal et al., 1962). A possible disadvantage is that there may be an excessive potassium loss. A hyperglycaemic action is known which may reveal latent diabetes mellitus (Goldner et al., 1960). Such an action increases the difficulties of management in established diabetes, but the effect appears to be reversible (Shapiro et al., 1961). Other complications are rare and there are few toxic reactions. Skin rashes, thrombocytopenic purpura, and pancreatitis are reported (Laragh, 1962), but so far no teratogenic effect has been seen.

Thiazides have been used in pre-eclampsia by several investigators. Finnerty et al. (1958) recorded a fall in blood-pressure of more than $20 \%$. Tatum and Waterman (1961) reported a reduced incidence of pre-eclampsia from $4 \%$ to $2 \%$ in 144 patients, but it is doubtful whether there is a concomitant reduction in the perinatal mortality (Soiva and Grönroos, 1963). Lennon (1959) suggested that the drug is better used prophylactically than therapeutically. The better results occur where a large dosage has been given.

\section{Present Investigation}

Plan of Trial.-The problem to be investigated was how chlorothiazide treatment, given to an out-patient, compared with a more usual treatment. A control group was to be treated with phenobarbitone, diet, and rest at home. Admission to hospital was to be the main standard by which success or failure was to be judged. Patients were allocated at random to one of two groups. Choice of treatment was determined by adding the last digit of the case-sheet number to the last digit of the patient's age. If this sum resulted in an even number chlorothiazide was given. Those with odd numbers received phenobarbitone therapy. The patients were told the nature of the treatment. Objections and refusals were rare, but if encountered the patients were rejected from the trial altogether and not moved to the opposite group. One mother did not take her phenobarbitone and another stopped her treatment because of a rash appearing. Three of the chlorothiazide group did not continue to take the tablets. Five cases were therefore discarded.

Selection of Cases.-Signs of mild or early toxaemia were taken as indications for treatment within the trial. No woman was admitted to the trial before the 24 th week of her pregnancy. There were three criteria. (1) a systolic blood-pressure of $140 \mathrm{~mm}$. $\mathrm{Hg}$ or more, or a diastolic pressure of $85 \mathrm{~mm}$. $\mathrm{Hg}$ and upwards. These readings were to be the lowest of three taken at 30-second intervals and after the patient had lain supine for five minutes. No correction was made for arm thickness, and the diastolic pressure was taken as the pressure at the " changing note"; (2) ankle oedema moderate or severe-if the oedema was thought to be due to varicosities then the patient was not admitted to the trial; (3) weight gain-the patients were weighed naked on a beam scale at each attendance. A gain in weight of $4 \mathrm{lb}$. $(1,814 \mathrm{~g}$.) or more in two weeks was regarded as evidence of early pre-eclampsia.
If one or more of these criteria were found the treatment was started. No case of albuminuria without one or two of the above signs was encountered.

\section{Schemes of Medication}

Chlorothiazide Group.-These women were given 0.5 g. of chlorothiazide twice daily together with varnished potassium chloride tablets $1 \mathrm{~g}$. twice daily. No rest, special diet, or sedation was recommended.

Phenobarbitone Group.-A low-salt 1,800-calorie diet was given to these patients. Full dietetic instruction was arranged and advice given on rest at home. Phenobarbitone $25 \mathrm{mg}$. was prescribed orally three times daily.

After a week of treatment the patient was reconsidered. If the signs of toxaemia had disappeared so that she no longer fell within the stated limits, then chlorothiazide was stopped, but women having phenobarbitone continued to receive it. Where there had been no deterioration in the condition but where the indications for treatment-namely, blood-pressure, oedema, or weight gain-still persisted, then chlorothiazide was given for a further week. This is distinct from the usual practice of prescribing the thiazides for short periods only. The choice was deliberate and represented an attempt to compare the hypotensive action of chlorothiazide with the diuretic action. On occasion, discontinuance of the chlorothiazide was followed by relapse, so that there was once more an indication for treatment, which was repeated. No patient was transferred from one group to the other, and the figures given below represent the number of patients treated, not the number of treatments given.

In a number of cases the condition worsened. Admission was advised if the blood-pressure rose to figures in excess of $145 \mathrm{~mm}$. $\mathrm{Hg}$ systolic or $85 \mathrm{~mm}$. $\mathrm{Hg}$ diastolic. Irrespective of blood-pressure, the patient was also admitted if she gained more than $2 \mathrm{lb}$. $(907 \mathrm{~g}$.) in weight during one week under treatment or if her oedema increased substantially. The appearance of non-infective albuminuria was regarded as an absolute indication for admission. Admission to hospital on account of preeclampsia was the end point of the trial. Subsequent progress and the final result of the pregnancy were recorded, but once she had been admitted the patient's treatment was conducted quite independently of the trial.

\section{Analysis of Cases}

In all, 105 mothers were selected for the trial. As has previously been mentioned, five of these cases were later rejected when it became clear that they had not taken the drugs prescribed for them. Of the remaining 100 women 46 were in the phenobarbitone and 54 in the chlorothiazide group.

It was hoped that the random selection would result in two similar groups, and examination of the records confirmed this. The age distribution was a close parallel (Table I).

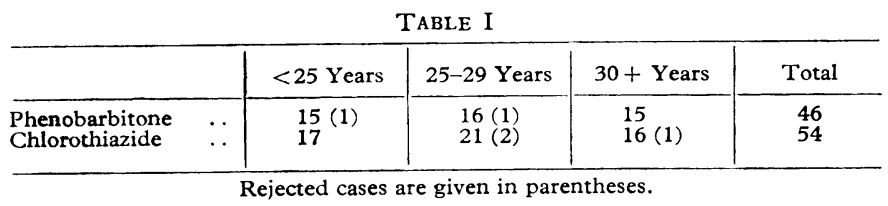

As regards parity, 38 women out of the 100 had had previous pregnancies, 20 of these patients being in the phenobarbitone and 18 in the chlorothiazide group. As the latter is the larger it will be seen that there is a greater proportion of primigravidae in this group $(67 \%)$ as compared with the phenobarbitone/diet group $(51 \%)$, but the difference is not significant. Within the phenobarbitone group there were two sets of twins, but neither 
mother was admitted to hospital on account of pre-eclampsia and neither developed hypertension.

The indications for treatment differed little between the two groups. Rather more women appeared to be admitted to the chlorothiazide group with excess weight gain or oedema (Table II), but a similar number in each group had oedema without hypertension.

\begin{tabular}{ll|c|c|c}
\multicolumn{5}{c}{ TABLE II } \\
\hline & $\begin{array}{c}\text { Weight Gain or } \\
\text { Oedema Only }\end{array}$ & $\begin{array}{c}\text { Raised Blood- } \\
\text { pressure }\end{array}$ & $\begin{array}{c}\text { Raised Blood- } \\
\text { pressure + } \\
\text { Weight Gain } \\
\text { or Oedema }\end{array}$ \\
\hline \begin{tabular}{ll|c} 
Phenobarbitone \\
Chlorothiazide ..
\end{tabular} & $\ldots$ & 15 & 31 & 20 \\
\hline
\end{tabular}

Albumin appeared in the urine of five women having phenobarbitone and of three women taking chlorothiazide.

\section{Duration of Treatment}

The length of treatment in the two groups cannot be compared, because the administration of phenobarbitone was continuous while that of chlorothiazide was intermittent. Five women were given less than $7 \mathrm{~g}$. of chlorothiazide. Seven had 7 to $14 \mathrm{~g}$. and 42 had more than $14 \mathrm{~g}$.

\section{Glycosuria}

One patient in the phenobarbitone group was found to be diabetic. Three patients having chlorothiazide developed glycosuria, but in each the fasting blood-sugar level was normal, as were their glucose-tolerance tests. Two of these women, and the diabetic patient, had children weighing over $8 \mathrm{lb}$. $(3,630 \mathrm{~g}$.) at birth.

\section{Results}

Where phenobarbitone and diet had been prescribed, 22 out of 46 patients were admitted on account of pre-eclampsia. Of the larger chlorothiazide group only 11 women required admission (Table III).

\begin{tabular}{|c|c|c|c|c|}
\hline & & Admitted & Not Admitted & Total \\
\hline \multirow[t]{2}{*}{$\begin{array}{l}\text { Phenobarbitone } \\
\text { Chlorothiazide .. }\end{array}$} & $\because$ & $\begin{array}{l}22 \\
11\end{array}$ & $\begin{array}{l}24 \\
43\end{array}$ & $\begin{array}{l}46 \\
54\end{array}$ \\
\hline & & 33 & 67 & 100 \\
\hline
\end{tabular}

Significantly fewer women required admission if they were receiving chlorothiazide. Both groups compare favourably with the overall admission rate for the previous year (Woolf, 1960) (Table IV).

TABLE IV

\begin{tabular}{|c|c|c|c|c|}
\hline & Admitted & $\begin{array}{c}\text { Not } \\
\text { Admitted }\end{array}$ & Total & $\begin{array}{c}\% \\
\text { Admitted }\end{array}$ \\
\hline $\begin{array}{l}\text { Chlorothiazide } \\
\text { Toxaemic patients (1960) } \\
\text { Phenobarbitone }\end{array}$ & $\begin{array}{r}11 \\
175 \\
22\end{array}$ & $\begin{array}{l}43 \\
48 \\
24\end{array}$ & $\begin{array}{r}54 \\
223 \\
46\end{array}$ & $\begin{array}{l}20 \\
78 \\
48\end{array}$ \\
\hline
\end{tabular}

Although these figures appear significant it is not reasonable to compare a group of women being given particular attention and close supervision by one clinician, with a general clinic population. However, the comparison between the two trial groups should be valid.

Mortality.-No eclampsia occurred within the two groups. No mothers died, but five children were lost. In the pheno- barbitone group there were one neonatal death and one stillbirth, and in the group having chlorothiazide one stillbirth and two neonatal deaths-one from haemorrhage associated with thrombocytopenic purpura and the other from prematurity. The mother of the child with thrombocytopenia had a total of $24 \mathrm{~g}$. of chlorothiazide over a six-weeks period. Examination of her blood showed no maternal thrombocytopenia. It should be remembered that this condition appears sporadically, without a known cause, in otherwise normal pregnancies (Willis, 1962). In fact, this patient has recently delivered herself of another affected child, no chlorothiazide having been given in the second pregnancy. The perinatal death rate for the trial is nearly 5\%. In 223 cases of pre-eclampsia seen in 1960 the perinatal mortality was $3.15 \%$ (Table V). This difference is not significant, but it is fair to conclude that there is no evidence of a reduced foetal wastage resulting from the treatment in the trial groups.

\begin{tabular}{|c|c|c|c|}
\hline & $\begin{array}{l}\text { Deaths and } \\
\text { Stillbirths }\end{array}$ & Survivors & Total \\
\hline \multirow{2}{*}{$\begin{array}{l}\text { Births in present trial } \\
\text { Births in toxaemic patients } \\
(1960)\end{array}$} & 5 & 97 & 102 (2 sets twins) \\
\hline & 7 & 217 & 224 (1 set , , ) \\
\hline
\end{tabular}

Anaemia.-To ensure that no depression of erythropoiesis was occurring routine haemoglobin estimation was carried out. For the purpose of comparison the haemoglobin on the fourth day of the puerperium is the figure quoted. Nine women in the barbiturate group had a haemoglobin of less than $10.5 \mathrm{~g}$., compared with 10 in the diuretic group. Seven estimates were omitted-two in the phenobarbitone group and five in the chlorothiazide group. Electrolytic imbalance was a possibility but none was demonstrated. Potassium shift from the myometrial cells has been described in prolonged labour (Hawkins and Nixon, 1958) and may affect uterine action. For this reason the length of labours was considered (Table VI). The difference is not significant, and no interference with labour need be anticipated as a result of chlorothiazide administration.

TABLE VI

\begin{tabular}{ll|c|c|c}
\hline & & $<12$ Hours & $12+$ Hours & Total \\
\hline Phenobarbitone &. & 30 & 16 & 46 \\
Chlorothiazide .. &.. & 37 & 17 & 54 \\
\hline & & 67 & 33 & 100 \\
\hline
\end{tabular}

Control of Blood-pressure and Fluid Retention.-It was expected that chlorothiazide would be the better treatment where temporary weight-reduction was required. What was not anticipated was the effectiveness of chlorothiazide in the control of blood-pressure and the disappointing effect of diet restriction in reducing weight. Chlorothiazide causes loss of weight in pregnancy in a significantly higher number of cases than can be achieved with diet and sedation (Table VII).

TABLB VII

\begin{tabular}{lc|c|c|c}
\hline & $\begin{array}{c}\text { Loss of Weight } \\
\text { on Treatment }\end{array}$ & $\begin{array}{c}\text { No } \\
\text { Loss }\end{array}$ & Total \\
\hline $\begin{array}{lll}\text { Phenobarbitone } \\
\text { Chlorothiazide .. }\end{array}$ & $\cdots$ & 12 & 34 & 46 \\
\hline & 38 & 16 & 64 \\
\hline & 50 & 50 & 100 \\
\hline
\end{tabular}

TABLE VIII

\begin{tabular}{|c|c|c|c|c|}
\hline & & Drop & No Drop & Total \\
\hline \multirow[t]{2}{*}{$\begin{array}{l}\text { Phenobarbitone } \\
\text { Chlorothiazide . }\end{array}$} & 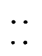 & $\begin{array}{l}11 \\
24\end{array}$ & $\begin{array}{l}35 \\
30\end{array}$ & $\begin{array}{l}46 \\
54\end{array}$ \\
\hline & & 35 & 65 & 100 \\
\hline
\end{tabular}


Blood-pressure Under Treatment.-There is in fact no significant difference between the two groups, but chlorothiazide is as good as phenobarbitone, rest, and diet in controlling bloodpressure (Table VIII).

\section{Discussion}

The benefit from chlorothiazide therapy in pregnancy may be due to the increased steroid production of pregnancy. Aldosterone is known to be present in the placenta in large quantities and bound cortisol levels in maternal plasma are raised. In the presence of aldosterone the thiazides cause an increased sodium/potassium exchange and a disproportionate sodium excretion ; cortisone merely increases the exchange. Excessive loss of fluid may predispose patients to thrombophlebitis, but in this series there was only one case of venous thrombosis.

At first the dosage was thought to be somewhat high, but the satisfactory response and the absence of severe toxic effects suggest that a high dose is both desirable and safe. There were three minor skin eruptions and a case of pruritus vulvae. apparently due to chlorothiazide. Two of the patients having phenobarbitone developed puerperal sepsis ; two having chlorothiazide exhibited symptoms of psychosis after delivery. In none of the four cases was the complication thought to be attributable to medication. Although no hyperglycaemia was seen in this series subsequent use has confirmed other workers' experience with chlorothiazide in diabetes. More recently administration of chlorothiazide to a diabetic mother for 24 hours has resulted in a threefold increase in blood sugar at 30 weeks of pregnancy. Diabetes mellitus is now considered to be a contraindication to treatment with thiazide derivatives. All other pregnant women who have hypertension, oedema, or excessive gain in weight appear to be suitable for early and prolonged treatment with this drug.

\section{Summary}

A group of 100 women were given random treatment with either phenobarbitone and diet restriction or chlorothiazide alone. From the point of view of enabling patients with mild pre-eclampsia to be treated as out-patients the chlorothiazide group is significantly better. Despite delayed admission the maternal results were good. The perinatal mortality was similar $-4.4 \%$ in the phenobarbitone group and $5.5 \%$ in the chlorothiazide group. The trial as a whole did not improve the perinatal mortality in the unit, but there was no significant increased foetal loss.

This project was planned originally by Mr. J. D. Martin and Dr. D. R. Laurence. A pilot study using different standards was begun by Dr. P. M. Spencer. I am indebted to these colleagues for allowing me access to their data. I am also grateful to Professor W. C. W. Nixon and Professor M. Rosenheim for their continuing interest and active encouragement, and to Mr. N. W. Please, of the statistics department, University College, who assisted in the analysis of the results.

\section{REFERENCES}

Dixon, H. G., Browne, J. C. McC., and Davey, D. A. (1963). Lancet, 2,

369.
Finnerty, F. A., Buckholz, J. H., and Tuckman, J. (1958). F. Amer. med. Ass., 166,141 .

Goldner, M. G., Zarowitz, H., and Akgun, S. (1960). New Engl. F. Med., 262, 403.

Hawkins, D. F., and Nixon, W. C. W. (1958). F. Obstet. Gynaec. Brit. Emp., 65, 895 .

Landesman, R., and Ollstein, R. N. (1958). In Symposium on Nontoxaemic Hypertension in Pregnancy, edited by $\mathrm{N}$. Morris and J. C. McC. Browne, p. 150. Churchill, London.

Laragh, J. H. (1962). Circulation, 26, 121.

Lennon, G. G. (1959). Symposium on the Use of Modern Diuretics in the Control of Hypertension, edited by W. W. Heseltine and P. J. Campbell, p. 65. Birchall, Liverpool.

Ministry of Health (1963). Reports on Public Health and Medical Subiects, No. 108.

Morris, N., Osborn, S. B., and Payling-Wright, H. (1955). Lancet, 1, 323. Morris, N., Osborn, S. B., and Payling-Wright, 2 ard 481.

Musgrove, F. (1950). University College Hospital Report of Obstetrical Registrar. U.C.H., London.

Pickering, G. W., Cranston, W. I., and Peas, M. A. (1961). The Treatment of Hypertension. Thomas, Springfield, Ill.

Shapiro, A. P., Benedek, T. G., and Small, J. L. (1961). New Engl. F. Med., 265, 1028.

Soiva, K., and Grönroos, M. (1963). Acta obstet. gynec. scand., 42, 12.

Tatum, H. J., and Waterman, E. A. (1961). GP (Kansas), 24, 101.

Thomas, S. (1957). 7. Physiol. (Lond.), 139, 337.

(1959). Ibid., 148, 489.

Villarreal, H., Revollo, A., Exaire, J. E., and Larrondo, F. (1962).

Circulation, 26, 409.
Willis, R. A. (1962). The Borderland of Embryology and Pathology, 2nd ed. Butterworth, London.

Wilson, G. M. (1963). Brit. med. F., 1, 285.

Woolf, A. J. (1960). University College Hospital Report of Obstetrical Registrar. U.C.H., London.
Contusions of the finger-tips are relatively common injuries and may result in an effusion of blood beneath the finger-nail, with or without an associated fracture of the terminal phalanx. Opinion regarding the management of this extremely painful condition of subungual haematoma is divided. All too often the lesion is regarded as a triviality, unworthy of surgical attention, and treatment is confined to the administration of analgesics. The pain can be relieved by operative decompression of the haematoma, and a number of methods for so doing are available. Dickson Wright (1952) recommends trephining the nail, as does Robins (1961), using a dental drill, the fine point of a scalpel, or the end of a length of wire (such as a

\footnotetext{
* From the Receiving-room, the General Infirmary at Leeds.
}

paper-clip) heated to red heat. To achieve the same effect, Flemming (1946) recommends cutting a triangular wedge from the most proximal area of the visible nail, while a similar procedure is involved in Kanavel's operation (as practised for paronychia), in which the proximal half of the nail is excised. Incision through the raised nail-bed is suggested by Ellis (1962), and where the haematoma has extended beneath the entire nail a distal incision beneath the tip of the nail may be made.

Despite the firm advocacy by these authors of their respective techniques, there is little information on their relative success in assuaging discomfort and in preserving the nail. Several of these methods are in use in the receiving-room of the General Infirmary at Leeds, where many of these injuries are treated annually, and it seemed that it might be useful to survey a 